\title{
LARYNGOLOGY
}

\section{The association between IncRNA H19 and EZH2 expression in patients with EBV-positive laryngeal carcinoma}

\author{
L'associazione dell'espressione di IncRNA H19 e EZH2 nei pazienti affetti \\ da carcinoma laringeo EBV positivo
}

\author{
Irina E. Hotoboc ${ }^{1}$, Alina Fudulu¹, Raluca Grigore ${ }^{2,3}$, Serban Bertesteanu²,3, Irina Huica ${ }^{1}$, lulia V. Iancu ${ }^{1}$, Anca Botezatu¹, \\ Coralia Bleotu', Gabriela Anton ${ }^{1}$ \\ ${ }^{1}$ Department of Molecular Virology, "Stefan S. Nicolau" Institute of Virology, Bucharest, Romania; 2 "Carol Davila" University of \\ Medicine and Pharmacy, Bucharest, Romania; ${ }^{3}$ ENT Department, Coltea Clinical Hospital, Bucharest, Romania
}

\begin{abstract}
SUMMARY
Objective. Laryngeal cancer is the second most common malignancy in the head and neck, with Epstein-Barr virus infection as a risk factor. Our aim is to evaluate correlations between the expression of IncRNA H19 and EBV infection in laryngeal cancer and H19 involvement in neoplastic progression through EZH2 association.

Materials and methods. 30 paired laryngeal tissue specimens (neoplastic and non-neoplastic) were included in the study. Nucleic acid isolation and cDNA synthesis was performed according to the manufacturer's protocol. EBV DNA and expression of lytic (BZLF1) and latent (LMP1) forms of infection were assessed in PCR assays; expression levels of H19 and EZH2 were quantified in qRT-PCR. Data was analysed using GraphPad Prism 5.0.

Results. Higher H19 relative expression in neoplastic vs paired non-neoplastic samples was found $(\mathrm{p}<0.0001)$ with a significant increase in EBV DNA positive neoplasms $(\mathrm{p}=0.0434)$. An inverse correlation between $\mathrm{H} 19$ and EZH 2 expression levels was noticed in EBV positive cases. Additionally, increased levels of H19 in LMP1 positive samples compared with those positive for BZLF1 was found $(\mathrm{p}=0.0593)$.

Conclusions. lncRNA H19 and EZH2 significantly contribute to the development of laryngeal carcinoma, being correlated with EBV infection markers.
\end{abstract}

KEY WORDS: lncRNA H19, EZH2, EBV, laryngeal carcinoma, infection marker

\section{RIASSUNTO}

Obiettivo. Il cancro della laringe è il secondo tumore maligno più comune della testa e del collo, l'infezione da virus Epstein-Barr (EBV) viene annoverata come fattore di rischio. Il nostro scopo è valutare le correlazioni tra l'espressione di lncRNA H19 e l'infezione da EBV nel cancro della laringe e il coinvolgimento di H19 nella progressione della neoplasia attraverso l'associazione di EZH2.

Materiali e metodi. Sono stati studiati 30 campioni di tessuto laringeo (neoplastici e non neoplastici). Si è proceduto all'isolamento degli acidi nucleici e alla sintesi del cDNA secondo specifico protocollo. Il DNA dell'EBV e l'espressione delle forme di infezione litica (BZLF1) e latente (LMP1) sono state valutate nei test con PCR; i livelli di espressione di $H 19$ ed EZH2 sono stati quantificati mediante qRT-PCR. I dati sono stati analizzati utilizzando GraphPad Prism 5.0.

Risultati. È stata trovata una maggiore espressione relativa di H19 nei campioni neoplastici rispetto a quelli non neoplastici $(p<0,0001)$ con un aumento significativo delle neoplasie positive al DNA di EBV $(p=0,0434)$. Una correlazione inversa tra i livelli di espressione di H19 ed EZH2 è stata notata nei casi positivi per EBV. Inoltre, è stato riscontrato un aumento dei livelli di H19 nei campioni LMP1 positivi rispetto a quelli BZLF1 ( $p=0,0593)$.

Conclusioni. IncRNA H19 ed EZH2 contribuiscono in modo significativo allo sviluppo del carcinoma laringeo, essendo correlati con i marker di infezione da EBV.

PAROLE CHIAVE: IncRNA H19, EZH2, EBV, carcinoma laringeo, marker di infezione
Received: March 4, 2021

Accepted: May 3, 2021

Published online: November 26, 2021

Correspondence

Alina Fudulu

"Stefan S. Nicolau" Institute of Virology, Department of Molecular Virology, 285 Mihai Bravu Ave, 030304 Bucharest, Romania

Tel./Fax +40 21324.25 .90

E-mail: alina.fudulu@ virology.ro

\section{Funding}

The study was supported by Project 433/ID 929/ SMIS code14049.

Authors contribution

All the authors have equal contribution.

Conflict of interest

The Authors declare no conflict of interest.

How to cite this article: Hotoboc IE, Fudulu A, Grigore R, et al. The association between lncRNA H19 and EZH2 expression in patients with EBV-positive laryngeal carcinoma. Acta Otorhinolaryngol Ital 2021;41:537-543. https://doi. org/10.14639/0392-100X-N1527

(c) Società Italiana di Otorinolaringoiatria e Chirurgia Cervico-Facciale

\section{(c) (1) $(2)$}

This is an open access article distributed in accordance with the CC-BY-NC-ND (Creative Commons Attribution-NonCommercial-NoDerivatives 4.0 International) license. The article can be used by giving appropriate credit and mentioning the license, but only for non-commercial purposes and only in the original version. For further information: https:// creativecommons.org/licenses/by-nc-nd/4.0/deed.en 


\section{Introduction}

Laryngeal carcinoma accounts for about $30-40 \%$ of head and neck malignancies ${ }^{1}$. A multitude of risk factors such as tobacco smoking, alcohol consumption, poor oral hygiene, occupational and socioeconomic status, dietary intake, hormonal factors and infectious agents have been associated with the development of laryngeal carcinomas. In fact, smoking and alcohol consumption have been shown to increase the risk of head and neck carcinoma, while genetic predisposition may play a role in the initiation of laryngeal neoplasms ${ }^{2}$. The synergistic actions create a local microenvironment favourable to the development and progression of laryngeal carcinoma. Epidemiological reports have shown a close association between viral infections and development of laryngeal neoplasms. Some studies have highlighted the role of herpesviruses in head and neck cancers, Epstein-Barr Virus (EBV) and Kaposi Sarcoma Herpes Virus (KSHV) being the best known oncogenic factors ${ }^{3}$. Polz-Gruszka et al. detected EBV in $57.5 \%$ of laryngeal and oropharyngeal carcinoma samples (laryngeal carcinomas accounting for $60 \%$ of these samples), indicating an important role of this virus in the development and progression of this malignancy ${ }^{2}$. Hasan et al. also detected (by in situ hybridization - ISH) EBV small non-coding RNAs (EBERs) in $12 / 30(40 \%)$ laryngeal carcinoma and 2/13 (15.4\%) benign laryngeal nodules, thus indicating viral contribution to laryngeal malignant neoplasms ${ }^{3}$. The EBV life cycle is divided into lytic and latent phases. The immediate-early BZLF1 gene (BamHI Z fragment leftward open reading frame 1) promotes EBV reactivation through its expressed protein, Zta, and subsequently initiates the expression of other EBV lytic genes in human epithelial cells. The transition between latent and lytic status might be linked to the ability of BZLF1 to bind to methylated viral promoters ${ }^{4,5}$. The role of BZLF1 in lytic-latent switch has been associated with impaired DNA damage repair and abrogation of the G2/M checkpoint, all leading to genomic instability in NPC (nasopharyngeal cancer) pathogenesis ${ }^{6}$. Among latent genes of EBV, LMP1 (latent membrane protein 1) exhibits an anti-apoptotic and cellular proliferative role leading to the development of oral squamous cell carcinoma ${ }^{7}$. Some authors have suggested that LMP1 plays an important role in invasiveness of nasopharyngeal epithelial cells in which its low levels may contribute to malignant transformation in the early stages of NPC pathogenesis. For instance, Al-Thawadi et al. found EBV LMP1 expression in 14/25 laryngeal neoplasms ${ }^{8}$. Over the past decade, research has focused on the association between lncRNAs (long non-coding RNAs) and cancers.
Some reports have illustrated that non-coding RNAs may be packed and secreted into circulating extracellular vesicles, thus playing a significant role in neoplasm growth, metastatic processes and angiogenesis initiation, and drug resistance. Thus, IncRNAs expression may have diagnostic and prognostic value, and many studies have investigated their potential as biomarkers ${ }^{9}$. Specific lncRNAs can lead to HNSCC (head and neck squamous cell carcinoma) carcinogenesis, including laryngeal cancer. Among these, H19 is suggested to be involved in the development of neoplastic cells and its overexpression in HNSCC has been associated with a low survival rate, a high risk of metastasis and disease recurrence ${ }^{10}$. According to other reports, miR-675, the mature product of this IncRNA, inhibits the expression of pro-apoptotic genes by targeting FADD (Fas-associated protein with death domain) in gastric cancer. EZH2 (Enhancer of zeste homolog 2) belongs to mammalian epigenetic PRC2 complex that contributes to trimethylation of $\mathrm{H} 3 \mathrm{~K} 27$, leading to chromatin silencing through its highly conserved SET domains in the Cterminus. Acting as both a transcriptional suppressor and co-activator, EZH2 has an important role in cancer development and progression ${ }^{11}$. The aim of this study was to evaluate the possible correlation between lncRNA H19 and neoplasm progression through EZH2 association in patients with EBV positive laryngeal cancer.

\section{Materials and methods}

\section{Sample collection}

The study was performed on 60 paired tissue specimens (neoplastic and adjacent non-neoplastic) obtained from 30 patients (median age 59.5 years; range $44-83$ years) diagnosed with laryngeal carcinoma, according to WHO criteria. Patient investigations and surgical interventions were performed in the Department of Otorhinolaryngology at Coltea Clinical Hospital, Bucharest. The pathological stage was determined according to TNM classification of the UICC. Clinical and epidemiological characteristics of the patients and samples are presented in Table I. The disease was significantly more frequent in men and smoking was a significant risk factor.

The pairs of laryngeal samples were obtained from patients diagnosed with laryngeal carcinomas who underwent surgery. The samples were preserved at $-80^{\circ} \mathrm{C}$ immediately after harvesting and stored until nucleic acid isolation. All samples were collected with the patient's informed consent and the study protocol was approved by the Ethic Committee of "St S. Nicolau" Institute of Virology (No 279/11.02.2019). 
Table I. The characteristics of study group.

\begin{tabular}{lcc}
\hline Gender & $\mathrm{M}$ & 28 \\
Age & $\mathrm{F}$ & 2 \\
& $<65$ & 15 \\
Smoking & 65 years & 15 \\
& Yes & 25 \\
T stage & No & 5 \\
& T1-T2 & 14 \\
N stage & T3-T4 & 16 \\
& N0 & 8 \\
& N1 & 14 \\
M stage & N2-N3 & 8 \\
& M0 & 26 \\
& M1 & 4 \\
\hline
\end{tabular}

\section{DNA isolation}

DNA isolation from tissues was performed using the High Pure PCR Template Preparation Kit (Roche Molecular Biochemicals, Mannheim, Germany), according to the manufacturer's instructions. The DNA concentration and purity of each sample was determined using a NanoDrop ND1000 spectrophotometer (Thermo Fisher Scientific Inc.). All DNA samples were stored at $-20^{\circ} \mathrm{C}$.

\section{EBV DNA detection}

EBV detection was performed by PCR using EBNA1 primers (Tab. II). The reactions were performed in $25 \mu \mathrm{l}$ volume mixture containing 5X PCR buffer (Promega GoTaq Green Flexi Buffer), $25 \mathrm{mM} \mathrm{MgCl}$ (Promega), $10 \mathrm{mmol}$ of each dNTP (Promega), 10 pmol of each EBNA1 forward and reverse primers, $5 \mathrm{U} / \mu \mathrm{l}$ Go-Taq DNA Polymerase (Promega) and $200 \mathrm{ng}$ of isolated DNA. PCR conditions were as follows: 45 cycles consisting of $94^{\circ} \mathrm{C}$ for 1 minute, $58^{\circ} \mathrm{C}$ for 40 seconds, $72^{\circ} \mathrm{C}$ for 40 seconds followed by an extension of 7 minutes at $72^{\circ} \mathrm{C}$. EBNA1 amplicons (138 bps) were visualized in $2 \%$ agarose gel electrophoresis, after staining with ethidium bromide.

\section{RNA isolation and cDNA synthesis}

Total RNA extraction from tissues was performed using Trizol Reagent (InvitrogenTM, Thermo Fisher Scientific Inc.), according to the manufacturer's instructions. $50 \mathrm{mg}$ of each tissue sample were disrupted using a homogeniser, and 1 $\mathrm{mL}$ of Trizol reagent was added. The samples were further purified using RNeasy Mini kit (Qiagen, Hilden, Germany), according to the manufacturer's instructions and stored at $-80^{\circ} \mathrm{C}$ until use. The purity and concentration of each RNA sample was determined using a NanoDrop ND1000 spectrophotometer (Thermo Fisher Scientific Inc.). The synthesis of cDNA was performed using Transcriptor First Strand cDNA Synthesis Kit (Roche Molecular Biochemicals, Mannheim, Germany) according to the manufacturer's instructions and each sample was stored at $-20^{\circ} \mathrm{C}$ until use.

BZLF1 and LMPI PCR assay

Primers and TaqMan probes targeting BZLF1 (BamHI Z

Table II. Sequence of primers used in the study.

\begin{tabular}{|c|c|c|c|}
\hline \multicolumn{2}{|c|}{ Primer name } & \multirow{2}{*}{$\begin{array}{c}\text { Primer sequence } \\
\text { 5'-TGATAACCATGGACGAGGAC-3' }\end{array}$} & Reference \\
\hline EBNA1 & Forward & & Kahla et al., ${ }^{12}$ \\
\hline & Reverse & 5'-CTTCAAGTTGCATTGGCTGC-3' & \\
\hline \multirow[t]{3}{*}{ BZLF1 } & Forward & 5'-AAATTTAAGAGATCCTCGTGTAAAACATC-3' & Ryan et al., ${ }^{13}$ \\
\hline & Reverse & 5'-CGC CTC CTG TTG AAG CAG AT-3' & \\
\hline & Probe & 5'-(6FAM)ATAATGGAGTCAACATCCAGGCTT GGGC(TAMRA)-3' & \\
\hline \multirow[t]{3}{*}{ LMP1 } & Forward & 5'-CAGTCAGGCAAGCCTATGA-3' & Ryan et al., ${ }^{13}$ \\
\hline & Reverse & 5'-CTGGTTCCGGTGGAGATGA-3' & \\
\hline & Probe & 5'-(6FAM)GTCATAGTAGCTTAGCTGAAC(TAMRA)-3' & \\
\hline \multirow[t]{2}{*}{ H19 } & Forward & 5'-TGCTGCACTITACAACCACTG-3' & Mohammadi et al., ${ }^{14}$ \\
\hline & Reverse & 5'-ATGGTGTCTTTGATGTTGGGC-3' & \\
\hline \multirow[t]{2}{*}{ U6 } & Forward & 5'-CTCGCTTCGGCAGCACATATACT-3' & Feng et al., ${ }^{15}$ \\
\hline & Reverse & 5'-ACGCTTCACGAATTTGCGTGTC-3' & \\
\hline \multirow[t]{2}{*}{ GAPDH } & Forward & 5'-CCATCTTCCAGGAGCGAGATCCCT-3' & lancu et al., 16 \\
\hline & Reverse & 5'-TGAGCCCCAGCCTTCTTCATGGT-3' & \\
\hline \multirow[t]{2}{*}{$\mathrm{EZH} 2$} & Forward & 5'-TGCAACACCCAACACTTATAAGCGG-3' & This study \\
\hline & Reverse & 5'-ССTTTGCTCССTCСАAATGCTGGT-3' & \\
\hline
\end{tabular}


fragment leftward open reading frame 1) and LMP1 (latent membrane protein-1) genes were used (Tab. II). PCR was performed in $25 \mu \mathrm{L}$ reaction volume $(100 \mathrm{ng} / \mu \mathrm{L}$ cDNA, 1X TaqMan Universal MasterMix, 25 pmol of each forward and reverse primer, and 10 pmol TaqMan probe) using iQ5 System (BioRad, California, USA). Thermocycling conditions were: $50^{\circ} \mathrm{C}$ for 2 minutes, $95^{\circ} \mathrm{C}$ for 10 minutes, followed by 40 cycles of $95^{\circ} \mathrm{C}$ for 15 seconds and $60^{\circ} \mathrm{C}$ for 1 minute. Specimens with $\mathrm{Cq}$ (quantification cycle) $<40$ in the FAM channel were considered positive.

\section{Quantitative real-time PCR analysis}

The expression levels of H19 and EZH2 were quantified in qRT-PCR on an iQ5 System (BioRad, California, USA) using Maxima SyBr Green/Fluorescein qPCR Master Mix $2 \mathrm{x}$ (Thermo Scientific Inc.) according to the manufacturer's instructions. Specific primers were designed for targeted genes using primer-BLAST (www.ncbi.nlm.nih.gov/tools/ primer-blast/). Primer sequences are presented in Table II. The expression levels of $\mathrm{H} 19$ were normalised using the U6 gene as reference while expression levels of EZH2 were normalized using GAPDH gene. Each sample was tested in duplicate. The qPCR data was analysed, and relative expression was calculated with $\mathrm{Cq}$ using $2^{-\Delta \mathrm{Cq}}$ method.

\section{Statistical analysis}

All statistical data was analysed using GraphPad Prism 5.0 (Graph Pad Software Inc., San Diego, CA, USA). The differences between two groups were analysed using $t$-test (Mann Whitney) and ANOVA (Kruskal-Wallis) for comparing three or more groups. Spearman non-parametric correlation was performed with $95 \%$ CI. In all cases, a $\mathrm{p}$ value $<0.05$ was considered statistically significant.

\section{Results}

The relative expression of lncRNA H19 in neoplastic and adjacent non-neoplastic laryngeal tissues was investigated using $\mathrm{qRT}-\mathrm{PCR}$ which revealed significantly higher expression $(\mathrm{p}<0.0001)$ in neoplastic samples (mean $=1.574 \pm 0.8629)$ vs paired non-neoplastic tissues $($ mean $=-0.4290 \pm 0.8666)($ Fig. 1A).

To investigate the clinical role of lncRNA H19 in laryngeal cancer, potential correlations of its expression levels with clinicopathological features were examined. Spearman non-parametric correlation was performed, and a positive association was noted between increases in IncRNA H19 expression with tumour size, although there was no significant difference between consecutive groups (T1/T2/T3/ T4). No association with the metastasis status (M0 vs M1) was observed. An increasing of $\mathrm{H} 19$ expression values with
$\mathrm{N}$ stage (N0/N1/N2\&3) was noted and significant differences between non-neoplastic tissue samples and N0 stage $(\mathrm{p}=0.0080)$ as well as between $\mathrm{N} 1$ stage and $\mathrm{N} 2 \& 3$ ones $(\mathrm{p}=0.0253)$ were found (Fig. 1B).

The expression levels of EZH2 in laryngeal cancer were evaluated ( $t$-test) in neoplastic versus non-neoplastic samples (Fig. 2A). Significant differences in EZH2 expression $(\mathrm{p}=0.0434)$ between neoplastic samples (mean $=-1.361 \pm 0.6765)$ and their non-neoplastic pair (mean $=-2.256 \pm 1.120)$ were found. Next, potential association of EZH2 expression levels with clinicopathological features was examined; $t$-test performed on these values revealed increased expression for samples collected from patients with N0 stage, which was significant compared with non-neoplastic $(\mathrm{p}=0.0040)$ and $\mathrm{N} 1$ samples $(\mathrm{p}=0.0010)$, and values similar with $\mathrm{NT}$ were found for $\mathrm{N} 1$ and $\mathrm{N} 2 / 3$ samples (Fig. 2B).

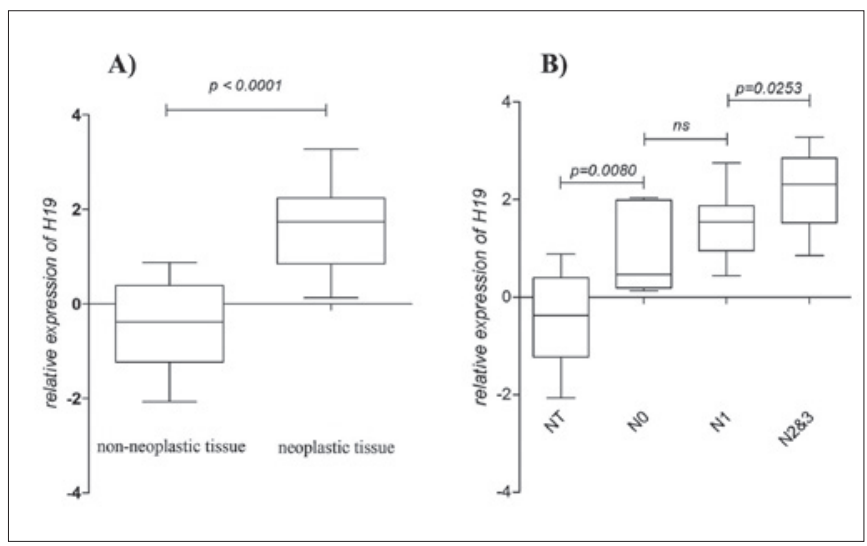

Figure 1. Relative expression levels of IncRNA H19 in neoplastic and adjacent non-neoplastic laryngeal tissue samples (A); relative expression levels of IncRNA H19 according to N stages (NT - non-neoplastic tissue samples) (B).

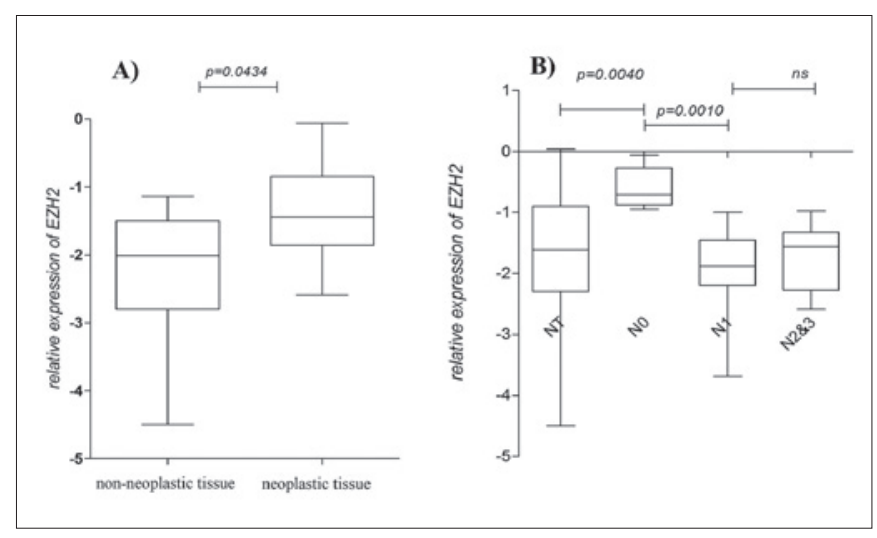

Figure 2. Relative expression levels of EZH2 in neoplastic vs adjacent nonneoplastic laryngeal tissue sample (A); relative expression levels of EZH2 according to N stages (NT - non-neoplastic tissue samples) (B). 


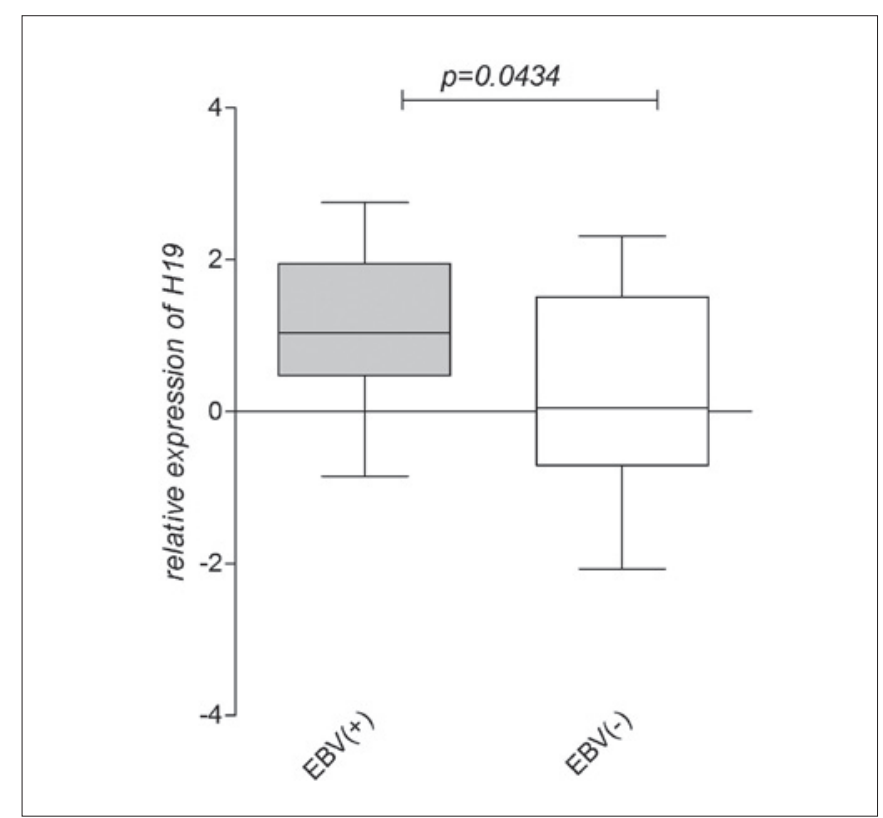

Figure 3. H19 expression levels in EBV-positive compared to EBV-negative neoplastic tissue.

Viral testing confirmed the presence of the EBV genome in $73.33 \%(22 / 30)$ of samples. The expression levels of H19 in EBV DNA positive vs EBV DNA negative samples was quantified. The results showed a significant increase of the expression of this lncRNA in viral-positive neoplasms $(\mathrm{p}=0.0434)$ (Fig. 3).

Spearman's correlation was used to investigate the relation between H19 and EZH2 expression levels in neoplastic samples (overall and EBV positive cases). The results indicated an inverse correlation between H19 and EZH2 expression levels in EBV positive cases, highlighting a viral influence in the development of this type of carcinoma (Fig. 4).

Markers of lytic and latent EBV infection were assessed by TaqMan PCR assay and the results showed the expression of BZLF1 in $31.82 \%$ and LMP1 in $18.18 \%$ of EBV positive cases. Association between the expression of $\mathrm{H} 19$ and EZH2 and EBV markers in patients with laryngeal cancer was further evaluated (Fig. 5).

We found increased gene expression levels of lncRNA H19 in LMP1 positive samples compared with BZLF1positive samples $(p=0.0593)$. In contrast, lower EZH2 gene expression levels were found in the LMP1 positive group versus the BZLF1 positive group.

\section{Discussion}

In the last years, the clinical importance of long non-coding RNAs has been recognised in different pathological pro-

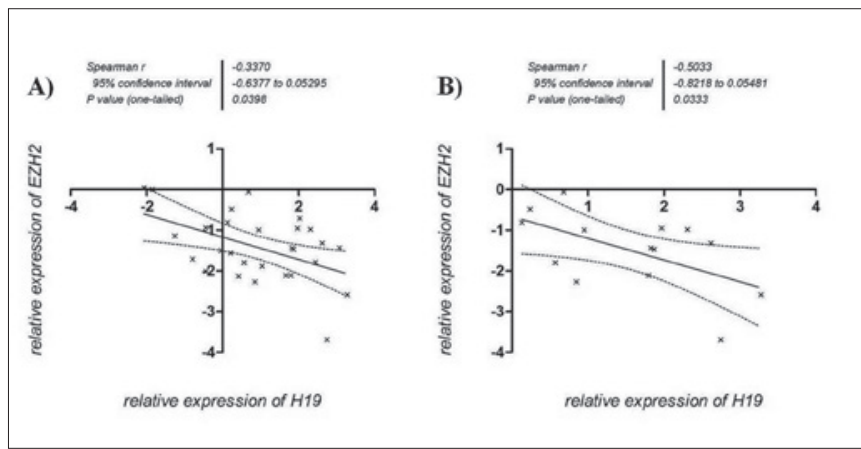

Figure 4. The correlation between $\mathrm{H} 19$ and EZH2 expression levels in neoplastic laryngeal samples (A) overall; (B) in EBV positive samples.

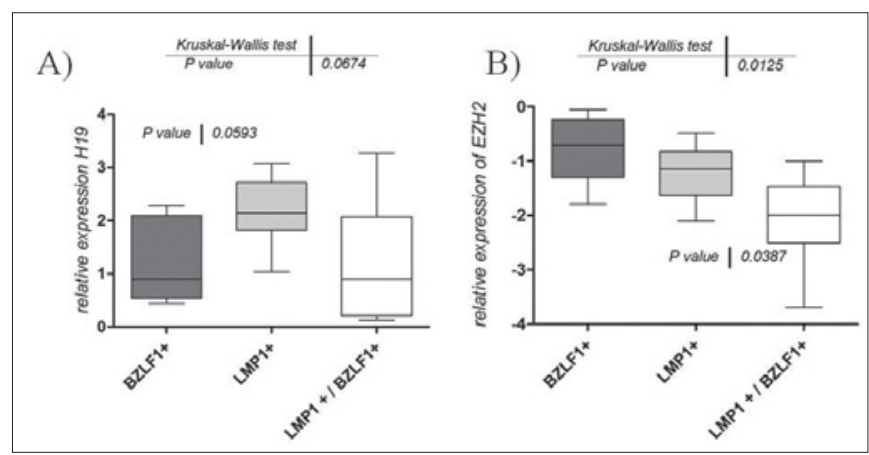

Figure 5. Relative expression of IncRNA H19 (A) and EZH2 (B) according to EBV markers in laryngeal carcinoma.

cesses associated with malignant diseases. Among these non-coding molecules, the potential of IncRNA H19 as a biomarker has been evaluated in various types of cancers. Many authors indicated that lncRNA H19 is overexpressed in cancer, thus suggesting its potential role in cell proliferation and tumorigenesis. lncRNA H19 overexpression was found in pancreatic ductal adenocarcinoma, a neoplasm with an increased mortality, together with HOTAIR, in plasma of patients with gastric cancer ${ }^{17}$. In this study, we found that lncRNA H19 was significantly upregulated in neoplastic versus normal tissue samples, and its expression was associated with tumour size and $\mathrm{N}$ stage. We also found significant differences between $\mathrm{H} 19$ expression levels in N0 stage samples versus non-neoplastic tissues, respectively, between the N1 stage and N2/N3 samples, but no significant association between lncRNA H19 and metastasis stages (M0 and M1) was found. In contrast to these results, some authors have reported a significant association of H19 levels with earlier lymph node metastasis, higher clinical stage, overall survival and disease-free survival ${ }^{18}$. Other meta-analysis revealed that lncRNA H19 expression levels were closely associated with histological grade, 
TNM stage and degree of neoplasm invasion in gastrointestinal cancer and that it could be linked to distant metastasis in gastrointestinal and non-gastrointestinal cancers ${ }^{19}$. We found increased H19 expression in EBV-positive laryngeal neoplasms compared with EBV-negative ones, thus suggesting a possible key-role of EBV as a viral oncogenic factor in initiation and progression of laryngeal neoplasms. EZH2 appears to play a dual role in cancer, either as an oncogene or tumour suppressor, so there are controversial reports regarding its expression levels in cancer. Increased risk of metastasis and increased aggressiveness of malignancy was found to be associated with loss of EZH2 in advanced stages ${ }^{20}$.

In our study, we have shown that EZH2 expression levels were increased in laryngeal neoplastic samples compared to normal samples, thus suggesting the important function of this histone-methyltransferase in cell proliferation. However, the higher expression levels were found in samples collected from patients with N0 stage, suggesting a better correlation with early development of this type of malignancy. In this study, we noticed a decrease in expression for patients with $\mathrm{N}+$ stage at levels comparable with those found in non-neoplastic tissue samples. Other results have indicated that EZH2 is overexpressed in laryngeal cell carcinoma versus non-neoplastic tissues and that this cellular epigenetic marker could be considered as a poor prognostic factor for nasopharyngeal and oral squamous cell carcinoma ${ }^{21}$. Relative expression levels of EZH2 have also been associated with $\mathrm{N}$ stage in laryngeal carcinoma, emphasising its role in the progression of carcinogenesis. No direct link between $\mathrm{H} 19$ and EZH2 has been reported, but rather through miR-630, an EZH2 repressor that interacts with $\mathrm{H} 19$ in a sequence-specific manner ${ }^{22}$. In this study, we found a negative correlation between H19 lncRNA and EZH2 expression levels with good values of Spearman correlation coefficient in neoplastic tissues samples, and even better in EBV-positive neoplastic samples, in both cases with statistical significance. Furthermore, a statistically significant association between H19, EZH2 expression and viral markers (BZLF1 and LMP1) presence could suggest various reliable interpretations, depending on EBV infection patient's status (latent infection, lytic reactivation). There is scant data in the literature regarding the relationship between EZH2 expression and EBV markers of lytic and latent infection. The study by Ichikawa et al. performed on Akata cells demonstrated through knock-down experiments the essential role of EZH2 in the regulation of viral latent and lytic genes in reactivation ${ }^{23}$. In this study, we found higher expression of H19 in LMP1 positive samples. LMP1 is the most important EBV oncoprotein which plays an important role in the transformation of EBV cells, and our results consolidate the finding that lncRNA H19 expression associates with latency and oncogenesis. This EBV gene can be detected in exosomes isolated from the serum of NPC patients, thus facilitating its potential as a biomarker and underlying a clinical importance in NPC pathogenesis ${ }^{24}$. On the other hand, Sun et al. found that LMP1 could upregulate EZH2 in LMP1 positive HONE-1 NPC cell line, while other authors have indicated that BZLF1 and BRLF1 promoters were correlated with a repressive hallmark of chromatin (H3K27me3), enhanced by an increased level of EZH2, in an EBV latent state ${ }^{25}$.

\section{Conclusions}

The clinical importance of this research it related to its potential application in molecular diagnostics of this malignancy. This can be explained by the large variability of the different diagnostic and prognostic biomarkers found in many neoplasms, and thus the viral and cellular biomarkers which play a specific role in LSCC development could offer an interesting view of this pathology.

We found increased lncRNA H19 expression in laryngeal neoplasms associated with clinicopathological features (N stage). The highest values of $\mathrm{H} 19$ expression were noticed in EBV-positive cases compared to EBV-negative ones with a close relationship between this non-coding molecule and EBV latent markers. On the other hand, an inverse correlation between lncRNA H19 and EZH2 in laryngeal neoplasms was found, thus suggesting the role of this histonemethyltransferase in cell proliferation. Further studies are needed to elucidate the interplay between viral and epigenetic factors in this pathology.

These future studies will be needed to better demonstrate the intimate relationship between viral markers (genes, non-coding products, proteins) and the cellular ones which define the entire variety of many signalling pathways from the following pathological processes (cellular proliferation, neoplastic angiogenesis, cellular invasion and metastasis, apoptosis, immune surveillance) involved in laryngeal cancer progression.

\section{References}

1 Al-Qudah MA, Al-Shaikh AF, Haddad HK, et al. Prevalence and detection of sexually transmitted cases of laryngeal carcinoma. Head Neck Pathol 2020;14:909-914. https://doi.org/10.1007/ s12105-020-01150-2

2 Polz-Gruszka D, Stec A, Dworzanski J, et al. EBV, HSV, CMV and HPV in laryngeal and oropharyngeal carcinoma in Polish patients. Anticancer Res 2015;35:1657-1662.

3 Li H, Liu S, Hu J, et al. Epstein-Barr virus lytic reactivation regulation and its pathogenic role in carcinogenesis. Int J Biol Sci 2016;12:13091318. https://doi.org/10.7150/ijbs. 16564 
4 Mohammed Ali SH, Alajeely AA-A, Al-Lebawy NS, et al. Molecular tracing of abundances of latent Epstein-Barr virus early repeats in laryngeal carcinomatous tissues from a group of Iraqi patients: a possibility of an early event in laryngeal carcinogenesis. Biochem Cell Arch 2018;18:421-427.

5 Chakravorty A, Sugden B, Johannsen EC. An epigenetic journey: Epstein-Barr virus transcribes chromatinized and subsequently unchromatinized templates during its lytic cycle. J Virol 2019;93:e02247-18. https://doi.org/10.1128/JVI.02247-18

6 Yang J, Deng W, Hau PM, et al. Epstein-Barr virus BZLF1 protein impairs accumulation of host DNA damage proteins at damage sites in response to DNA damage. Lab Invest 2015;95:937-950. https://doi. org/10.1038/labinvest.2015.69

7 Heawchaiyaphum C, Iizasa H, Ekalaksananan T, et al. Epstein-Barr virus infection of oral squamous cells. Microorganisms 2020;8:419. https://doi.org/10.3390/ microorganisms8030419

8 Al-Thawadi H, Gupta I, Jabeen A, et al. Co-presence of human papillomaviruses and Epstein-Barr virus is linked with advanced tumor stage: a tissue microarray study in head and neck cancer patients. Cancer Cell Int 2020;20:361. https://doi.org/10.1186/s12935-020-01348-y

9 Wang M, Zhou L, Yu F, et al. The functional roles of exosomal long non-coding RNAs in cancer. Cel Mol Life Sci 2019;76:2059-2076. https://doi.org/10.1007/s00018-019-03018-3

10 Song W, Sun Y, Lin J, et al. Current research on head and neck cancer-associated long noncoding RNAs. Oncotarget 2018;9:1403-1425. https://doi.org/10.18632/oncotarget.22608

11 Gan L, Yang Y, Li Q, et al. Epigenetic regulation of cancer progression by EZH2: from biological insights to therapeutic potential. Biomark Res 2018;6:10. https://doi.org/10.1186/s40364-018-0122-2

12 Kahla S, Oueslati S, Achour M, et al. Correlation between EBV coinfection and HPV16 genome integrity in Tunisian cervical cancer patients. Braz J Microbiol 2012;43:744-753. https://doi.org/10.1590/ S1517-83822012000200039

13 Ryan JL, Fan H, Glaser SL, et al. Epstein-Barr virus quantitation by real-time PCR targeting multiple gene segments. J Mol Diagn 2004;6:378-385. https://doi.org/10.1016/S1525-1578(10)60535-1

14 Mohammadi K, Baghini SS, Saremi MA. Increased expression of the lncH19 gene in the plasma of people with breast cancer. Pers Med 2020;5:12-14. https://doi.org/10.22034/PMJ.2020.43454
15 Feng Y, Kang Y, He Y, et al. MicroRNA-99a acts as a tumor suppressor and is down-regulated in bladder cancer. BMC Urology 2014;14:1-8. https://doi.org/10.1186/1471-2490-14-50

16 Iancu IV, Botezatu A, Plesa A, et al. Alterations of regulatory factors and DNA methylation pattern in thyroid cancer. Cancer Biomark 2020;28:255-268. https://doi.org/10.3233/CBM-190871

17 Zhou X, Yin C, Dang Y, et al. Identification of the long noncoding RNA H19 in plasma as a novel biomarker for diagnosis of gastric cancer. Sci Rep 2015;5:11516. https://doi.org/10.1038/srep11516

$18 \mathrm{Yu} \mathrm{H}, \mathrm{Li} \mathrm{S}, \mathrm{Wu} \mathrm{Sx}$, et al. The prognostic value of long non-coding RNA H19 in various cancers. Medicine 2020;99:e18533. https://doi. org/10.1097/MD.0000000000018533

19 Jing W, Zhu M, Zhang XW, et al. The significance of long noncoding RNA H19 in predicting progression and metastasis of cancers: a meta-analysis. Biomed Res Int 2016;2016:5902678. https://doi. org/10.1155/2016/5902678

20 Böhm J, Muenzner JK, Caliskan A, et al. Loss of enhancer of zeste homologue 2 (EZH2) at tumor invasion front is correlated with higher aggressiveness in colorectal cancer cells. J Cancer Res Clin Oncol 2019;145:2227-2240. https://doi.org/10.1007/s00432-019-02977-1

21 Huang J, Zhou L, Chen H, et al. EZH2 is overexpressed in laryngeal squamous cell carcinoma and enhances the stem-like properties of AMC-HN-8 cells. Oncol Lett 2016;12:837-846. https://doi. org/10.3892/ol.2016.4704

22 Li X, Lin Y, Yang X, et al. Long noncoding RNA H19 regulates EZH2 expression by interacting with miR-630 and promotes cell invasion in nasopharyngeal carcinoma. Biochem Biophys Res Commun 2016;473:913-919. https://doi.org/10.1016/j.bbrc.2016.03.150

23 Ichikawa T, Okuno Y, Sato Y, et al. Regulation of Epstein-Barr virus life cycle and cell proliferation by histone H3K27 methyltransferase EZH2 in Akata cells. mSphere 2018;3:e00478-18. https://doi. org/10.1128/mSphere.00478-18

24 Shair KHY, Reddy A, Cooper VS. New insights from elucidating the role of LMP1 in nasopharyngeal carcinoma. Cancers 2018;10:86. https://doi.org/10.3390/cancers 10040086

25 Sun W, Chen L, Tang J, et al. Targeting EZH2 depletes LMP1-induced activated regulatory $\mathrm{T}$ cells enhancing antitumor immunity in nasopharyngeal carcinoma. J Can Res Ther 2020;16:309-319. https://doi. org/10.4103/jcrt.JCRT_986_19 